\title{
Análise das características ergonômicas das poltronas de salas de cinema e a sua influência no conforto do usuário
}

Analysis on the ergonomic characteristics of a movie theater's seats and how they influence the user comfort

Isabela Almeida Sales Evaristo

Universidade Estadual de Londrina - UEL

isabelaevaristo41@gmail.com

뜬

Renan Geovani Mansano

Universidade Estadual de Londrina - UEL

mansanodesign@gmail.com

ar

Vitória Cereia Zambrim

Universidade Estadual de Londrina - UEL

vickyzambrim@gmail.com

M

Cristiane Affonso de Almeida Zerbetto

Universidade Estadual de Londrina - UEL

cra@uel.br

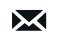

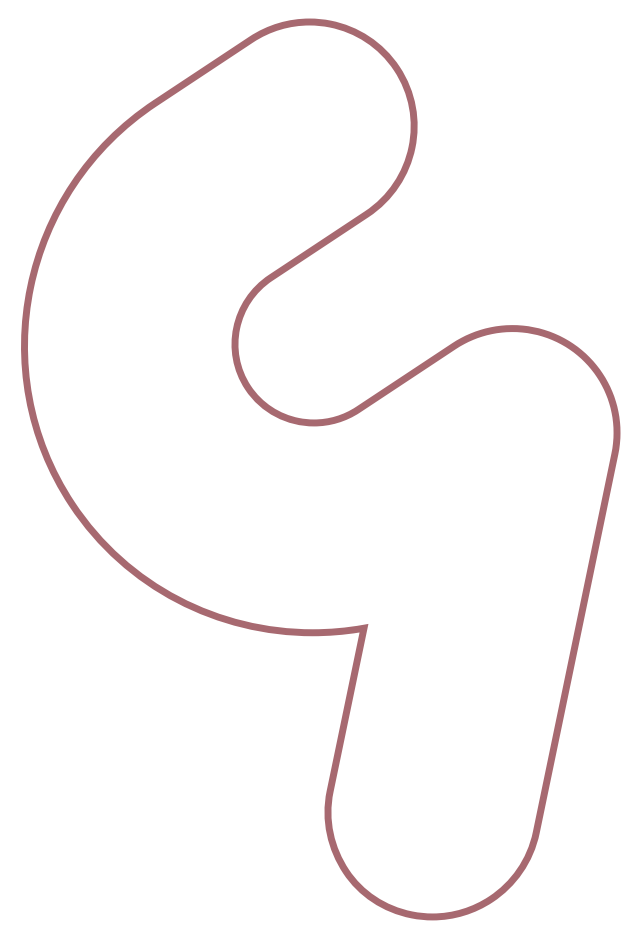

PROJËTICA

\section{COMO CITAR ESTE ARTIGO:}

EVARISTO, Isabela Almeida Sales; MANSANO, Renan Geovani; ZAMBRIM, Vitória Cereia; ZERBETTO, Cristiane Affonso de Almeida. Análise das características ergonômicas das poltronas de salas de cinema e a sua influência no conforto do usuário. Projética, Londrina, v. 11, n. 2, p. 104-125, 2020.

DOI: $10.5433 / 2236-2207.2020 v 11 n 2 p 104$

Submissão: 19-04-2018

Aceite: 22-05-2019

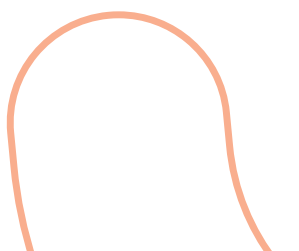


RESUMO: Esta pesquisa teve como objetivo realizar uma investigação acerca das poltronas de salas de projeção cinematográfica, considerando sua funcionalidade e nível de conforto proporcionado ao usuário. Com esta análise foi possível retirar dados pertinentes dos fatores que funcionam e os que não funcionam, entender sobre a experiência do usuário e quais os critérios que esse público utiliza para a escolha de seus assentos. Por fim, estes dados foram relacionados à base teórica e, principalmente aos aspectos ergonômicos de conforto.

Palavras-chave: Conforto do usuário. Assento. Cinema. Postura.

ABSTRACT: This research describes an investigation on a movie theater's seats, considering their functionality and the level of comfort provided to the user. This analysis allowed the extraction of relevant data on factors that work and those that don't, understanding the user experience and which criteria the audience takes into account while choosing their seats. Lastly, these data were related to the theoretical basis - especially the ergonomic aspects of comfort.

Keywords: User comfort. Seat. Movie theater. Posture.

\section{INTRODUÇÃO}

A nova dinâmica do século XXI está modificando drasticamente os hábitos dos seres humanos, que estão permanecendo grande parte de seu tempo na posição sentada, tanto em seus períodos de trabalho quanto em períodos de lazer. Já que isso acontece, é preciso que esses indivíduos se sintam confortáveis durante os momentos em que estiverem nessa posição, para evitar possíveis danos a sua estrutura física, como pode ser explicado pela ergonomia. 
A ergonomia é o ramo que se dedica à compreensão das interações entre o ser humano e outros elementos de um sistema, aplicando teorias, princípios, dados e métodos para esses objetos, de modo a otimizar o bem-estar humano e o desempenho geral do sistema (INTERNATIONAL ERGONOMICS ASSOCIATION, 2018). E essa necessidade de compreender essas interações tornou-se ainda mais essencial pelo fato do ser humano associar seus hábitos de lazer com a posição sentada, tais como a manipulação de dispositivos eletrônicos (computador, consoles de games, entre outros) e se esses aspectos ergonômicos não estiverem presentes nos objetos que envolvem suas atividades, podem acabar acarretando em problemas futuros relacionados a saúde e bem-estar desses indivíduos.

Um dos ambientes mais populares para atividades de lazer presentes nos dias atuais são os cinemas, grandes salas de projeção utilizadas para o entretenimento, onde seu público permanece boa parte do tempo na posição sentada. Existem normas, segundo a Associação Brasileira de Cinematografia (2009), que especifica como essas poltronas devem ser instaladas e as características essenciais para uma boa experiência nas salas de projeção.

A partir desta contextualização, o presente artigo abordará questões a respeito da ergonomia de poltronas de cinema, por meio de uma pesquisa bibliográfica e um levantamento junto aos usuários, buscando conhecer elementos decisivos no momento da escolha e da experiência no uso das poltronas das salas de projeção cinematográfica.

A lógica dessa pesquisa, além de entender os conceitos que envolvem as poltronas de cinema, é levantar questionamentos sobre quais características ergonômicas são levadas em consideração no momento da fabricação desses objetos, quais são aplicadas na prática, por que algumas não são empregadas e como isso reflete na experiência do usuário e, por fim, confrontar os dados levantados com as bases teóricas pesquisadas. 


\section{REVISÃO BIBLIOGRÁFICA}

"Numa situação ideal, a ergonomia deve ser aplicada desde as etapas iniciais do projeto [...] Estas devem sempre incluir o ser humano como um de seus componentes." (IIDA, 2005, p. 19).

lida (2005) aborda a questão do assento dizendo que este é, provavelmente, uma das invenções que mais contribuiu na modificação do comportamento humano. Atualmente, muitas pessoas chegam a passar mais de 20 horas nas posições deitada e sentada, levando a acreditar que a espécie humana deixou de ser um animal ereto (homo erectus) para se transformar no animal sentado (homo sedens). É justamente a partir desta nomenclatura que deriva-se o termo sedentário, que significa sentado.

O problema do assento é um item que tem despertado grande interesse entre os pesquisadores em ergonomia, desde o séc. XVIII são feitas análises sobre posturas, especialmente por Andry (1743), que fez diversas recomendações para corrigir más posturas que causam fadiga, dores lombares e cãibras, e que se não forem corrigidas podem causar dano permanente à coluna.

Em relação ao conforto, lida (2005) o caracteriza como uma sensação subjetiva, produzida quando não há nenhum tipo de pressão localizada sobre o corpo. Registrar a frequência das mudanças de postura é um método de avaliação de níveis de conforto, sendo que uma frequência elevada indica desconforto.

É difícil estabelecer as características exatas de conforto no assento, pois cada pessoa se adapta melhor a um certo tipo de assento, além de que há um tipo de assento para cada ocasião, fazendo com que o conforto seja influenciado por outros fatores, além de preferências individuais e aparência estética. (CORLETT, 1989 apud IIDA, 2005). 
O conceito de conforto de Linden (2007) é o mesmo que lida cita em sua obra. "O conceito de conforto é subjetivo, depende em grande parte da percepção da pessoa que está vivendo aquela situação, não existindo uma definição universalmente aceita" (LINDEN, 2007, p. 63). Mesmo depois de muitos avanços, o significado de conforto ainda traz polêmica nos meios acadêmicos de Ergonomia e do Design. $\mathrm{O}$ autor destaca que existem duas correntes, uma que entende que o conforto e o desconforto estão em oposição, e outra que considera o conforto e o desconforto duas dimensões diferentes.

Desde a década de 50, a definição de conforto tem estado aparente na apresentação de estudos ergonômicos, especificamente associados à assentos. A primeira definição operacional foi proposta por Hertzberg, nesta visão conforto é um estado mental que ocorre na "ausência de sentimentos de desconforto" (LUEDER, 1983, p. 701). Assim, não seria possível medir ou observar diretamente a ocorrência de conforto. A única maneira de avaliá-lo seria por meio da declaração do indivíduo sobre como ele se sente. O conforto está associado ao bem-estar, seu significado depende do objeto e da situação vivenciada.

Keith Slater (1985, p. 4) define o conforto como "um estado prazeroso de harmonia fisiológica, física e psicológica entre o ser humano e o ambiente". Os aspectos fisiológicos estão ligados ao funcionamento do corpo humano, os aspectos psicológicos dizem respeito ao conforto mental, e os aspectos físicos correspondem com a interação com o ambiente. A partir desta definição, Coelho, Gonçalves e Dahlman (2000) fizeram uma experiência, e com base em algumas características da mesma, e da definição de Slater (1985), foi possível organizar opções que serviram como um modo de avaliação de cada sujeito entrevistado, sendo elas:

- A dimensão fisiológica que corresponde à interface humana constituída pelo assento (dureza do assento, conforto térmico); 
- O conforto físico que depende de aspectos posturais e biomecânicos (alcance, visão e mobilidade);

- A dimensão psicológica que está relacionada à tarefa de condução (familiaridade na posição do lugar e no assento). (COELHO; GONÇALVES; DAHLMAN, 2000).

- De acordo com lida (2005), do ponto de vista ergonômico, todos os produtos, independente de seu tamanho ou complexidade, tem o propósito de satisfazer certas necessidades humanas; desta forma, direta ou indiretamente, os produtos entram em contato com o indivíduo. O autor então propõe três características básicas que os produtos devem ter para que funcionem bem em suas interações com os seus usuários, sendo elas:

- Qualidade técnica: o que faz o produto funcionar, seja do ponto de vista mecânico, elétrico, eletrônico ou químico. Deve-se levar em consideração a eficiência com que o produto executa sua função, a facilidade de limpeza, a manutenção e assim por diante;

- Qualidade ergonômica: o que garante uma boa interação entre produto e usuário, inclui a facilidade de manuseio, adaptação antropométrica, fornecimento claro de informações, facilidade de "navegação", compatibilidade de movimentos, entre outros itens de conforto e segurança;

- Qualidade estética: o que proporciona prazer ao consumidor, envolvendo a combinação de formas, cores, materiais, texturas, acabamentos e movimentos de maneira a tornar o produto atraente e desejável aos olhos do consumidor. (IIDA, 2005).

Em qualquer tipo de produto, estas três qualidades se encontram presentes, sendo que uma ou outra pode predominar sobre as outras, dependendo do caso. 
Projética, Londrina, v. 11, n. 2, p. 104-125, agosto 2020

Existem normas definidas pela (ABC) Associação Brasileira de Cinematografia (2009) que auxiliam na arquitetura e disposição de elementos físicos que compõem as salas de projeção cinematográfica.

Dentre esses elementos temos as poltronas, objetos de conforto que auxiliarão na experiência do usuário. A Associação Brasileira de Cinematografia (2009) define que a distância mínima desses elementos com a tela de projeção deve ser igual ou superior a $60 \%$ da largura da tela, e a sua angulação máxima deve ser igual ou inferior a 30 graus para locais onde o campo de visão incida pelo centro da tela e 40 graus no caso desse campo incidir pela borda superior.

A poltrona mais distante da tela de projeção deve se encontrar com a sua face anterior do encosto a uma distância igual ou inferior ao dobro da largura dessa tela. Os assentos devem permanecer em planta baixa e entre dois planos verticais, apresentar linhas de visão abaixo de um plano que passe pela borda superior da tela, com uma inclinação de 110 graus e devem estar dispostas de forma que seja preservado um escalonamento visual igual ou superior a 0,15 metros (uma distância entre o topo da cabeça e o nível dos olhos), considerando-se uma altura de 1,20 metro entre o nível dos olhos e o piso segundo a Associação Brasileira de Cinematografia (2009).

Há também normas a respeito do modo correto de enfileirar essas poltronas, sendo um grupo de cinco fileiras onde quatro formem um retângulo e uma fique no centro. Já o espaçamento entre poltronas (tanto pela frente como por trás), considera a distância de um encosto traseiro de um assento ao outro, e esta deve ser igual ou superior a 1 metro. (Associação Brasileira de Cinematografia, 2009)

Todas estas considerações servirão de base para a avaliação do produto em foco. 


\section{DESCRIÇÃO DO MÉTODO}

Os métodos utilizados para o desenvolvimento desta investigação foram a pesquisa narrativa juntamente com o estudo de caso.

A pesquisa narrativa, segundo Clandinin e Connely (2000) é definida como um método de estudo, havendo quatro formas de empregá-la, no artigo foi utilizado o modo de Clandinin e Connely (2000), eles a definem como "uma forma de entender a experiência" em um processo de colaboração entre pesquisador e pesquisado. A pesquisa narrativa pode ser descrita como um método que consiste na coleta de histórias sobre determinado tema onde o investigador encontrará informações para entender certo fenômeno.

As histórias podem ser obtidas por meio de várias ferramentas: entrevistas, diários, autobiografias, gravação de narrativas orais, narrativas escritas e notas de campo.

No caso da pesquisa aqui apresentada foi aplicada a entrevista junto aos usuários do produto investigado.

Já o estudo de caso, de acordo com Gil (2002), é uma modalidade de pesquisa amplamente utilizada nas ciências biomédicas e sociais. Consiste em realizar um estudo profundo e exaustivo de um ou poucos objetivos, para permitir o seu amplo e detalhado conhecimento.

É geralmente utilizado nas ciências biomédicas para um estudo-piloto de esclarecimento do campo da pesquisa, seus resultados são apresentados em aberto, ou seja, na condição de hipóteses e não em conclusões. 
Foi encarado com preconceito durante muito tempo, por ser considerado um procedimento pouco rigoroso, que serviria somente para estudos da natureza exploratória. Hoje, é considerado um procedimento de delineamento mais adequado para a investigação de um fenômeno contemporâneo dentro de seu contexto real, onde os limites entre o contexto e o fenômeno não são claros. Nas ciências sociais, essa distinção entre fenômeno e contexto tende a ser complicada, e isso dificulta no tratamento dos problemas mediante os procedimentos caracterizados por alto nível de estruturação.

Assim, segundo Gil (2002, p. 54) as ciências sociais utilizam o estudo de caso para as seguintes situações:

- Explorar situações da vida real, onde os limites não são claramente definidos;

- Preservar o caráter unitário do objeto estudado;

- Descrever a situação do contexto em que está sendo feita determinada investigação;

- Formular hipóteses ou desenvolver teorias;

- Explicar as variáveis causais de determinado fenômeno em situações muito complexas que não possibilitam a utilização de levantamentos e experimentos.

Após as explanações sobre os métodos, salientamos que estes foram aplicados no estudo de caso de poltronas de um (01) cinema na cidade de Londrina - PR, o qual não autorizou a publicação das imagens e especificações técnicas do produto. Como narrativa foi usada a entrevista online estruturada a partir dos parâmetros ergonômicos abordados na revisão bibliográfica.

A realização das entrevistas ocorreu nos meses de outubro e novembro de 2017 junto à 145 usuários do cinema investigado. Esta entrevista teve como instrumento o questionário composto de nove perguntas entre abertas e fechadas. A seguir serão apresentados os resultados obtidos. 
Análise das características ergonômicas das poltronas... conforto do usuário EVARISTO, I. A. S. et al

"Numa situação ideal, a ergonomia deve ser aplicada desde as etapas iniciais do projeto [...] Estas devem sempre incluir o ser humano como um de seus componentes." (IIDA, 2005, p. 19.)

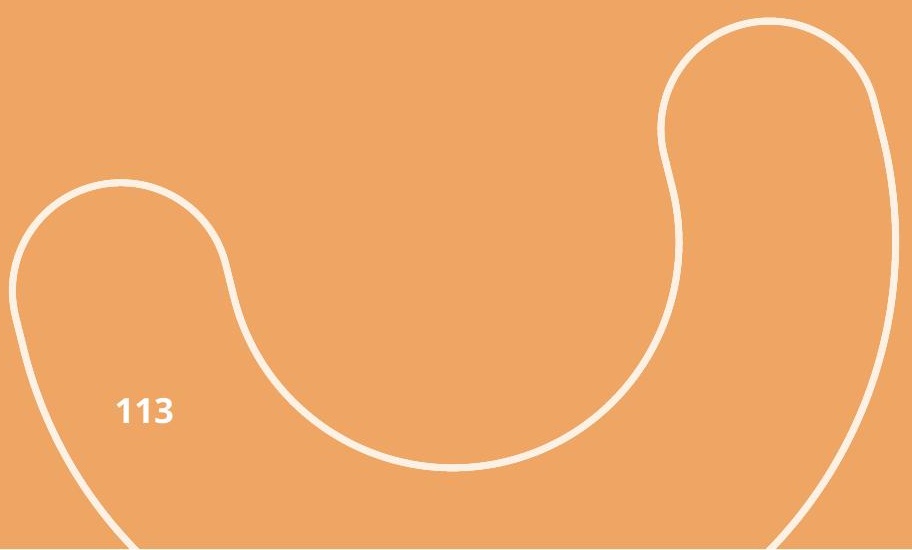




\section{RESULTADOS E DISCUSSÕES}

A entrevista online teve suas respostas representadas em gráficos para melhor entendimento e acessibilidade das informações, além do texto explicativo.

A primeira pergunta abordou a questão da frequência com a qual os entrevistados visitam o cinema, para que se tenha uma noção da experiência que o usuário detém sobre o tópico em questão. A questão contava com alternativas fixas, contudo, foi dada ao participante a opção de redigir seu próprio texto, caso sua escolha não se encaixasse nas alternativas apresentadas. A maioria dos entrevistados informou que frequentava o cinema mensalmente, contabilizando em $60,7 \%$ do total de participantes, seguido pela alternativa "anualmente", com $11,7 \%$. Alguns entrevistados não deixaram claro o quanto frequentavam o cinema, $6,9 \%$ respondeu com "às vezes" ou algo similar, seguido da opção "trimestralmente" que contabilizou 5,5\% e, então, 4,8\% contabilizados para a opção "raramente ou nunca", seguida por "semanalmente" com 4,1\%. As alternativas restantes receberam três votos cada, sendo elas: semestralmente, a cada dois meses e depende da programação.

Gráfico 1 - Frequência de ida ao cinema

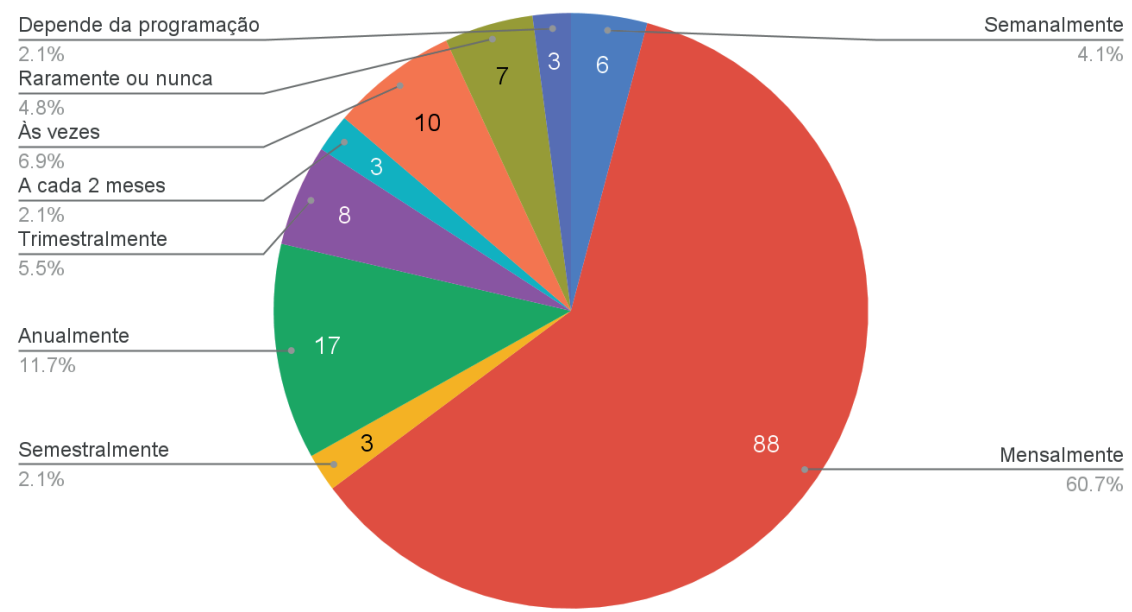

Fonte: Elaborado pelos autores. 
A segunda questão funcionou de modo parecido à anterior, nesta foi perguntado o critério considerado pelo usuário na hora de escolher seu lugar na sala de cinema e foram apresentadas duas alternativas fixas, sendo elas a posição e a distância até a tela, além da opção dada ao usuário de redigir seu próprio texto.

Dos entrevistados, a maioria, contabilizando $52,4 \%$ do total, respondeu que o critério considerado na hora da escolha é a distância até a tela, a posição ficou em segundo lugar com 39,3\% dos votos, e tanto a posição quando a distância contabilizou 7,6\% dos votos. Apenas uma pessoa escreveu a opção "campo de visão e imersão".

\section{Gráfico 2 - Critério(s) considerado(s) na escolha do lugar}

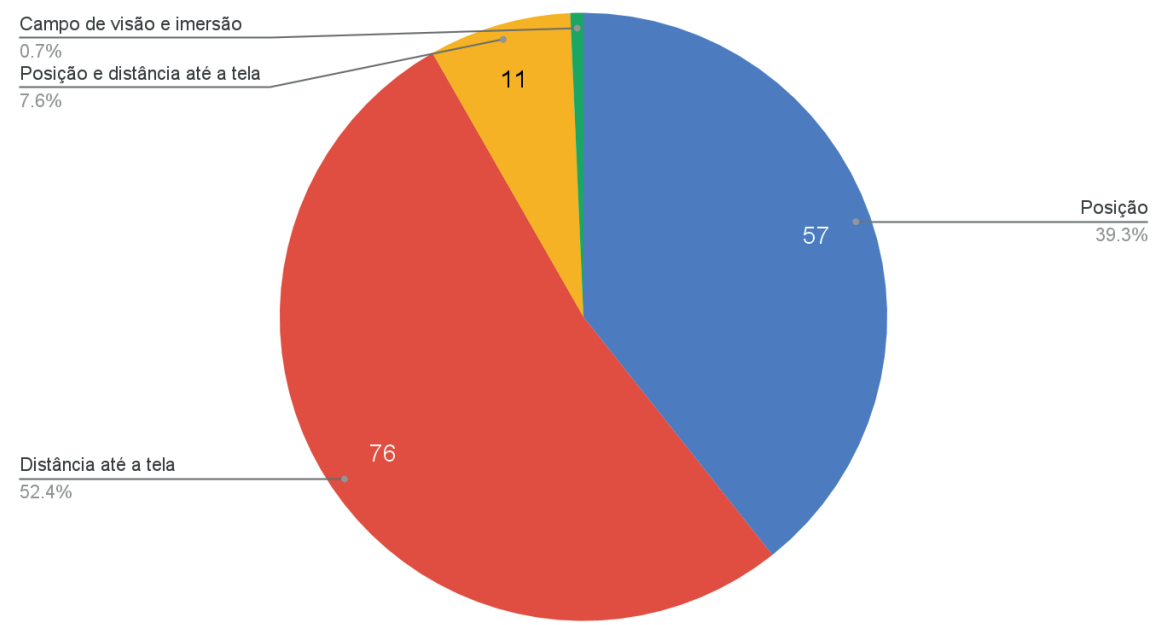

Fonte: Elaborado pelos autores.

A terceira questão abordou a qualidade das poltronas, com alternativas predefinidas disponíveis ao entrevistado. No geral, a classificação do objeto de estudo foi favorável, com $76,6 \%$ dos entrevistados elegendo os assentos como bons, apenas uma pessoa classificou o assento como péssimo e, entre um e outro, $17,2 \%$ consideraram ótimo e 5,5\% consideraram ruim. 
Gráfico 3 - Qualidade das poltronas do cinema estudado

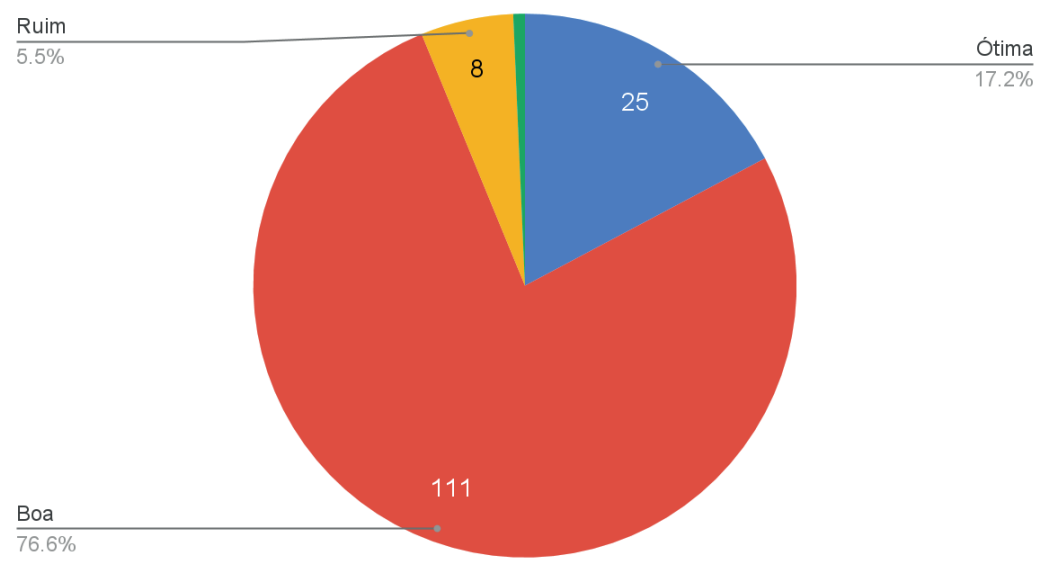

Fonte: Elaborado pelos autores.

A quarta pergunta abordou a questão da frequência com que se muda de postura em uma sessão, foram cedidas ao entrevistado três alternativas, das quais ele poderia escolher entre muita, pouca e nenhuma. Dos 145 interrogados, 53,8\% mudam muito de postura em uma sessão, $42,8 \%$ mudam pouco e $3,4 \%$ não mudam de postura.

\section{Gráfico 4 - Frequência na mudança de postura}

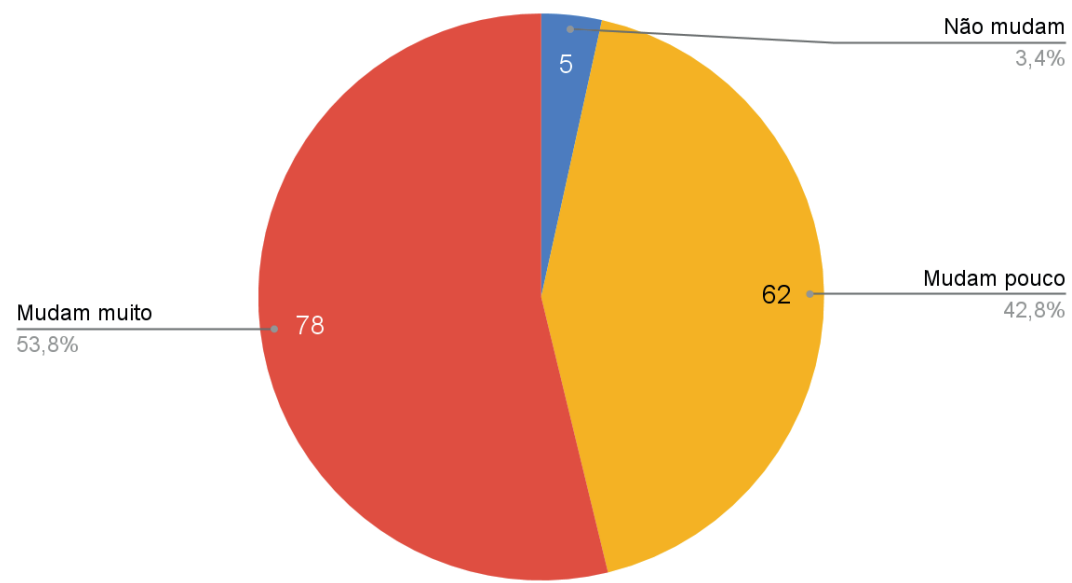

Fonte: Elaborado pelos autores. 
A pergunta seguinte propôs aos participantes responderem se eles já sentiram algum desconforto muito intenso durante ou após uma sessão, por conta das poltronas, esta provia ao entrevistado selecionar entre sim ou não. 67,6\% das pessoas escolheram não, 32,4\% responderam que sim. 0 objetivo desta questão era descobrir se realmente as poltronas poderiam ser desconfortáveis. Caso tenha sido respondido sim na questão anterior, os entrevistados deveriam, na pergunta seguinte, retratar qual tipo de desconforto foi experienciado durante ou após uma sessão.

Gráfico 5 - Sensação de desconforto muito intenso durante ou após uma sessão, por conta do assento

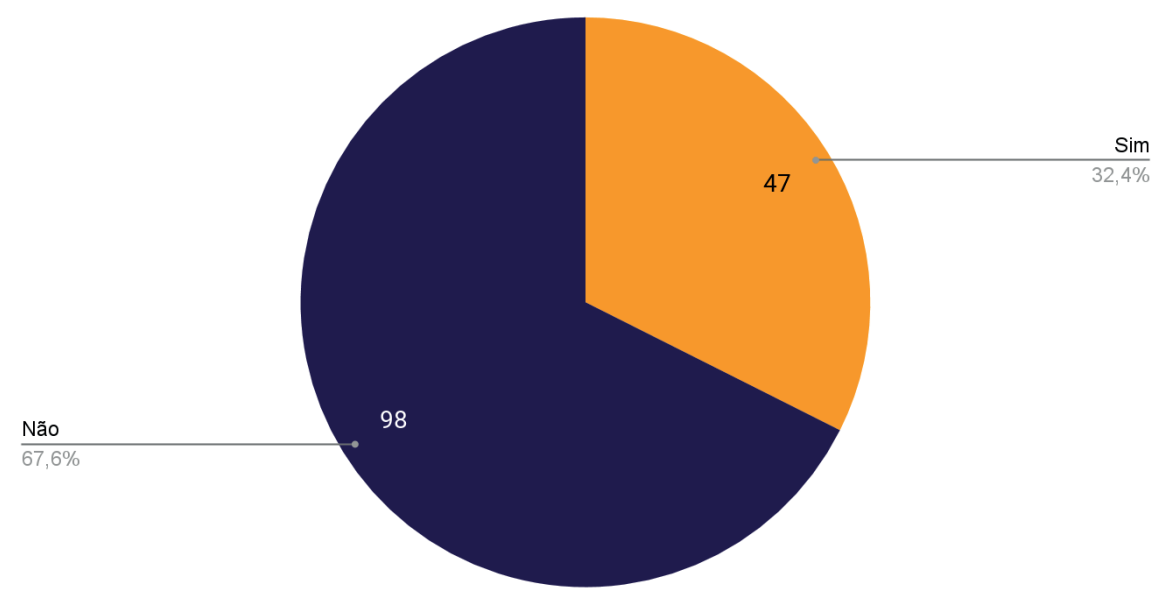

Fonte: Elaborado pelos autores.

Dos 47 que responderam sim, a maioria sentiu dores no corpo, especificamente nas costas, no pescoço, nas pernas, nos braços, nos ombros; desses, alguns classificaram sua dor por cãibras e fadigas, outros comentaram que sentiram um certo incômodo por conta da distância das poltronas e da falta de espaço para posicionar as pernas. Esta pergunta foi formulada com o intuito de mostrar onde as poltronas mais importunavam os indivíduos. 
Gráfico 6 - Tipo de desconforto experienciado

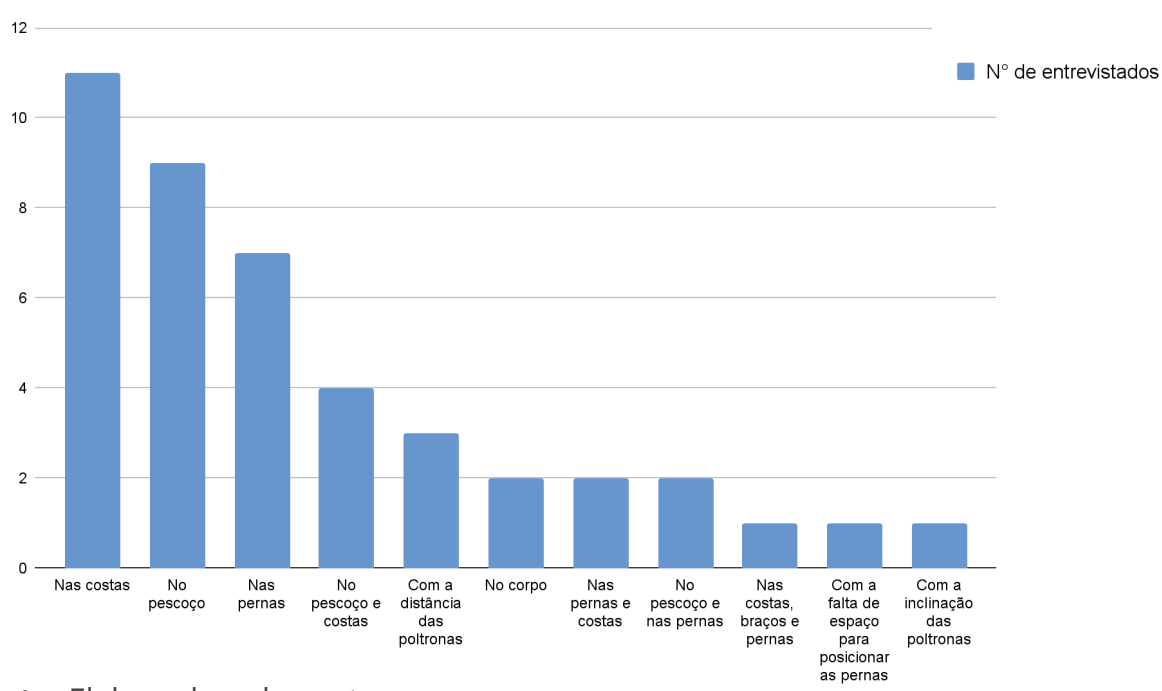

Fonte: Elaborado pelos autores.

A questão 7 foi dividida em duas alternativas, classificadas como A e B. A alternativa A questionou se o couro é um bom material na construção das poltronas do cinema, tendo como respostas duas opções: "Sim" ou "Não". Na alternativa A, dos 145 entrevistados, 115 responderam "Sim", totalizando 79,3\%, e 30 responderam "Não", definindo os restantes $20,7 \%$.

Gráfico 7 - Se o couro é um bom material utilizado na construção das poltronas

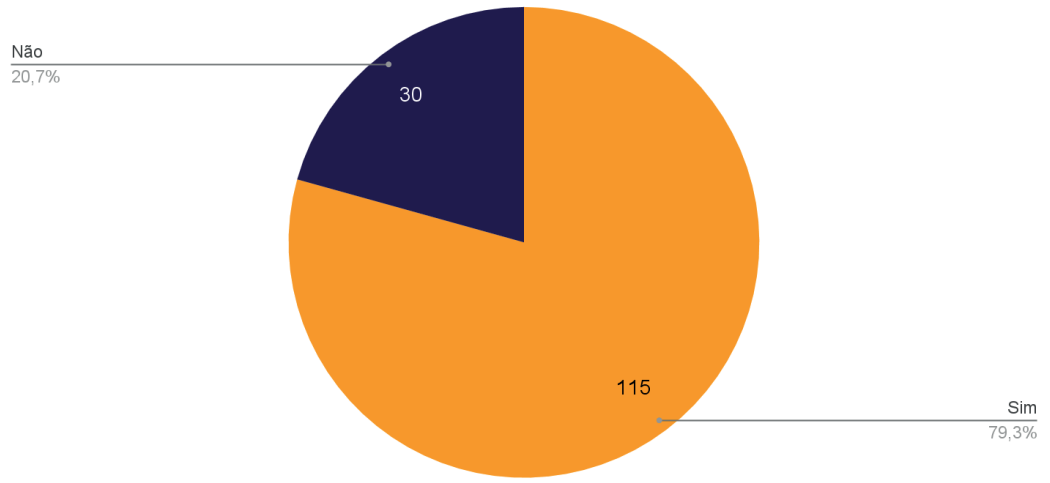

Fonte: Elaborado pelos autores. 
A alternativa B se limitou aos indivíduos que escolheram a segunda opção na alternativa A, com o objetivo de conhecer quais os possíveis materiais que essas pessoas escolheriam no lugar do couro. Dos 30 participantes do questionário que escolheram a resposta "Não", 8 indivíduos não opinaram e 4 não souberam o que opinar, já as demais 22, em sua maioria, não mencionaram um material específico, mas indicaram características ergonômicas que poderiam ser proporcionadas por outros tipos de materiais, como:

- Materiais que prezam o conforto e não produzam ruídos sonoros;

- Materiais que não provoquem calor;

- Materiais que não grudem na pele ou possam gerar algum tipo de irritação;

- Materiais menos rígidos que o couro;

- Materiais de fácil limpeza.

Entretanto, dessas 22 respostas, alguns nomes de materiais puderam ser citados, sendo eles:

- Veludo;

- Algodão;

- Tecido impermeável;

- Tecidos não especificados;

- Viscoelástico em plástico duro;

- Couro sintético;

- Materiais almofadados.

A questão 8 foi sobre a influência negativa da posição e da altura das poltronas de cinema na visibilidade do filme, sendo limitada a duas alternativas de escolha, "Sim" ou "Não". Do resultado obtido, mais da metade dos entrevistados, 86, responderam "Não", totalizando 59,3\% das respostas, porém, os demais 59 participantes totalizaram $40,7 \%$, que responderam sim, simbolizando um resultado 
significativo para a questão do nível de interferência desses elementos presente nas poltronas para a visibilidade do filme.

A questão 9 questionou os participantes sobre possíveis sugestões que eles poderiam oferecer à pesquisa para melhorar a qualidade das poltronas das salas do cinema. Dos 145 entrevistados, somente 51 responderam essa questão, sendo que somente 1 pessoa não ofereceu sugestão aparente e outras 2 enviaram respostas que desviavam do tema original da pesquisa.

As respostas foram variadas, mas em sua maior parte, os participantes ofereceram dados relacionados a elementos para a melhoria do conforto e da experiência de usuário, atrelados aos aspectos ergonômicos, tais como:

- Possibilidade de poder alterar a inclinação das poltronas: sugestões a respeito desse tópico foram as mais enviadas por parte dos entrevistados, que mencionaram a falta de mecanismos para a inclinação das poltronas (em salas normais do cinema). Esse tópico muitas vezes estava relacionado ao conforto e o bem-estar do usuário no momento do filme, por questões de comodidade;

- Ajuste do espaçamento entre fileiras de poltronas: esse foi o segundo item mais indicado, segundo as respostas enviadas, e se dividiram em duas especificações:

* Ajuste do espaçamento entre as fileiras de poltronas para a circulação de outros usuários: muitos indivíduos relataram a dificuldade da circulação, tanto por parte de outros usuários que se movimentam passando pela poltrona deles, quanto desses indivíduos em relação a outros já assentados;

* Ajuste dos espaçamentos entre as fileiras de poltronas para evitar que a poltrona da frente atrapalhe a visibilidade da projeção: foi mencionada 
a influência do tamanho de uma poltrona em relação à poltrona da frente, e como isso pode acabar atrapalhando a visibilidade do filme (tema recorrente da questão 8);

- Apoio reclinável para as pernas/pés e para braços e apoiadores de copos: esse foi o terceiro tópico de sugestões, por parte dos entrevistados que responderam essa questão.

O que mais foi abordado pelos participantes, foi:

- A falta de um mecanismo reclinável para as pernas;

- A falta de mobilidade do apoio para os braços e a necessidade desse item ser não compartilhável, logo, cada poltrona deveria apresentar apoiadores individuais, podendo evitar possíveis constrangimentos;

- Apoiadores de copos com maior mobilidade, para serem levantados dependendo da necessidade do usuário.

As demais sugestões foram enviadas pelo restante dos participantes, apresentam o mesmo teor relacionado a elementos de conforto e necessidade, como:

- Apoio para o pescoço com tamanho maior;

- Formatos adequados ao corpo dos usuários;

- Ajustes para pessoas com diferentes valores de altura;

- Compartilhamento para guardar objetos;

- Atribuir um caráter ortopédico para essas poltronas através da ergonomia;

- Ajustes para pessoas com obesidade;

- Evitar o uso de materiais que possam provocar ruídos sonoros;

- Considerações sobre o ambiente em que estão essas poltronas;

- Mudanças para o sistema de inclinação, levando em consideração o ajuste manual e não automático (por peso corporal); 
Projética, Londrina, v. 11, n. 2, p. 104-125, agosto 2020

- Melhorar o tamanho e conforto dessas poltronas;

- Poltronas medianas;

- Poltronas mais largas;

- Melhorar ângulo do assento;

- Utilizar outros cinemas e salas de projeção como referência.

Algumas sugestões foram deixadas de fora dos resultados, por se tratarem de respostas que desviam do tema original da pesquisa, estando associadas à características de outros produtos.

\section{CONSIDERAÇÕES FINAIS}

A partir dos resultados, podemos concluir que a respeito da indagação inicial foram vistos quais aspectos ergonômicos, relacionados ao conforto e bem-estar estão ou não sendo aplicados na prática, dentre estes é possível destacar o espaçamento entre as poltronas, o tipo de material escolhido na concepção das mesmas e a possibilidade de inclinação.

Mesmo respeitando as normas para a instalação das poltronas de cinema e alguns aspectos ergonômicos que esses objetos apresentam, para uma minoria dos participantes foi constatado uma certa deficiência fornecida pelas salas de projeção do cinema em questão, que deveriam ofertar ao usuário um bem-estar pleno em suas horas de entretenimento e lazer.

Em alguns casos, essa deficiência acaba fornecendo ao indivíduo uma má experiência, devido aos problemas já destacados, porém gostaríamos de ressaltar um deles, sendo a limitação da liberdade de escolha, já que é concedido aos usuários uma única alternativa de poltrona e, mesmo tendo sido considerada confortável a uma parcela dos usuários, a falta de elementos individuais e mecanismos retráteis e de maior inclinação acaba não proporcionando um conforto pleno ao restante desses indivíduos. 
Análise das características ergonômicas das poltronas... conforto do usuário

Para a implementação de grande parte dos ajustes apontados como interessante aos usuários, seria necessária a expansão do espaço das salas de projeção cinematográfica, além de outras modificações, como por exemplo a troca da própria matéria-prima.

Para finalizar, podemos dizer que muitas vezes são ignorados ou não recebem a devida atenção que merecem estes apontamentos dos usuários, pois essas alterações na estrutura física do ambiente e do produto apresentariam um custo maior para as empresas, que na maioria das vezes escolhem permanecer do modo em que se encontram atualmente, contudo atendendo à população de forma mediana. 


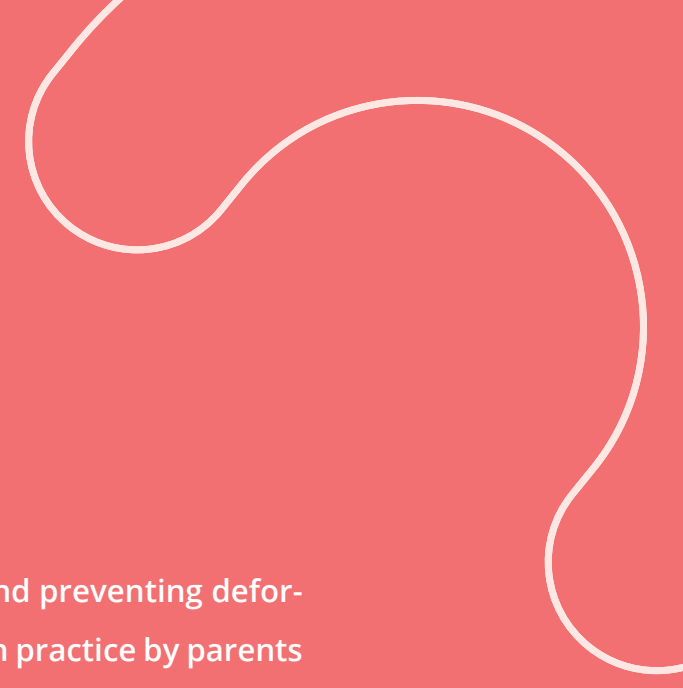
themselves, and all such as are employed in educating children. To which is added, a defence of the orthopaedia, by way of supplement / by the author. Londres: A. Millar, 1743.

2. ASSOCIAÇÃO BRASILEIRA DE CINEMATOGRAFIA - ABC. Recomendação técnica: arquitetura de salas de projeção cinematográfica. Rio de Janeiro: ABC, 2009. 11p. RT 001. Disponível em: http://www.abcine.org.br/uploads/artigos/ abc_rt_001_p_2009_rev_nov2009.pdf. Acesso em: 23 nov. 2017.

3. CLANDININ, D. Jean; CONNELLY, F. Michael. Pesquisa narrativa: experiência e história em pesquisa qualitativa. San Francisco: Jossey-Bass, 2000.

4. COELHO, Denis A.; GONÇALVES, Luís Carrilho; DAHLMAN, Sven. Componentes do conforto. In: CONGRESSO BRASILEIRO DE ERGONOMIA, 10., Rio de Janeiro, RJ. Anais [...]. Rio de Janeiro: ABERGO, 2000. CD-ROM.

5. GIL, Antônio Carlos. Como classificar as pesquisas? que é estudo de caso? In: GIL, Antônio Carlos. Como elaborar projetos de pesquisa. 4. ed. São Paulo: Atlas, 2002. Cap. 4, p. 54-55.

6. IIDA, Itiro. Ergonomia: projeto e produção. 2. ed. São Paulo: Blucher, 2005.

7. INTERNATIONAL ERGONOMICS ASSOCIATION - IEA. What is ergonomics. Disponível em: https://www.iea.cc/whats/. Acesso em: 19 abr. 2018.

8. LINDEN, Júlio Van Der. Prazer no uso de produtos. In: LINDEN, Júlio Van Der. Ergonomia e design: prazer, conforto e risco no uso de produtos. Porto Alegre: UniRitter, 2007. Cap. 3, p. 63-78. 
Análise das características ergonômicas das poltronas... conforto do usuário EVARISTO, I. A. S. et al

9. LUEDER, Rani Karen. Seat comfort: a review of the construct in the office environment. Human Factors, Santa Monica, CA, v. 25, n. 6, p. 701-711, 1983. Disponível em: https://www.humanics-es.com/LuederErgonomicsSeatComforthumanFactorsAndErgonomicsSociety.pdf. Acesso em: 29 jan. 2018.

10. SLATER, Keith; THOMAS, Charles C. Human comfort. Illinois: Springfield, 1985. 